\title{
PARTIAL LEAST SQUARES FOR SIMULTANEOUS DETERMINATION OF FE(III) AND HG(II) IN WATER AND PHARMACEUTICAL PREPARATIONS BY RP-HPLC USING 1,4-BIS-(4-PYRIDIL)-2,3-DIAZO-1,3-BUTADIENE CHELATING AGENT
}

\author{
MOHAMMADREZA KHANMOHAMMADI*, MAJID SOLEIMANI, MAJID AFSHAR, \\ AMIR BAGHERI GARMARUDI
}

Chemistry Department, Faculty of Science, IKIU, Qazvin, Iran

Running Head: RP-HPLC determination of Fe(III) and $\mathrm{Hg}(\mathrm{II})$ by 4-bpdb chelating

(Received: January 3, 2011 - Accepted: April 12, 2011)

\begin{abstract}
A method has been developed for simultaneous determination of $\mathrm{Fe}(\mathrm{III})$ and $\mathrm{Hg}(\mathrm{II})$ by RP-HPLC, utilizing partial least squares technique. Vertex $\mathrm{C}_{18}$, with UV-visible detector was applied in reversed phase high performance liquid chromatography, while 1,4-bis-(4-Pyridil)-2,3-diazo-1,3-butadiene (4-bpdb) was added to the mobile phase as the chelating agent. Several effective parameters e.g. mobile phase make up, buffers, concentration of 4-bpdp and pH salts were investigated in order to optimize the quantification conditions. The optimum condition was achieved at $25^{\circ} \mathrm{C}, 10 \%$ methanol containing mobile phase, 30 mmol $\mathrm{L}^{-1}$ acetate buffer, $0.05 \mathrm{mmol} \mathrm{L}^{-1} 4-\mathrm{bpdb}$ and $\mathrm{pH}=4.5$. Partial least squares chemometric technique was applied. The root mean square error (RMSE) of independent test set in the optimized model was 0.024 and 0.393 for $\mathrm{Fe}(\mathrm{III})$ and $\mathrm{Hg}(\mathrm{II})$ respectively.
\end{abstract}

Keywords: Determination; Complexation; 1,4-bis-(4-Pyridil)-2,3-diazo-1,3-butadiene; Mercury ; Iron ; RP-HPLC, PLS;

\section{INTRODUCTION}

Quantitative and qualitative analysis of heavy metals e.g. mercury in different media is of particular importance. The toxicity of mercury is known to be highly dependent on its chemical form. In many of the reported methods, a pre-concentration step should be included in the analysis procedure in order to achieve a final concentration level matching the detection limits accessible by applied detection technique ${ }^{1}$. Mercury has been also considered as a human health hazard. In the other hand, iron is of great interest to different fields of science. It is strongly involved in global biogeochemical cycling ${ }^{2}$. Several efforts have been taken for development of methods which provide accurate and precise separation and determination of these metal ions in biological, pharmaceutical, food and environmental samples during the last decades. There are several analytical methods described in the literature for the determination of mercury and iron at low concentrations in environmental and biological samples ${ }^{3}$. Although the most widely used determination method for the speciation of metals e.g. mercury in environmental samples is gas chromatography with capture electrode or with other atomic element specific detectors ${ }^{4,5}$, the use of HPLC for mercury speciation has the advantage of simplified sample preparation. In GC analysis, it is essential to form volatile, thermally stable derivatives, whereas this is not necessary for HPLC ${ }^{1}$. During the last decades high-performance liquid chromatography (HPLC) in combination with various detection techniques has been extensively applied to the speciation of a number of metal ions. Many chromatographic techniques have been applied for the analysis of $\mathrm{Hg}(\mathrm{II})$ and $\mathrm{Fe}(\mathrm{III})$, e.g. thin layer chromatography, ion exchange chromatography, ion pair chromatography and micro HPLC. Combination of chemometrics with analytical chemistry can improve selectivity of determination, optimize the experimental conditions, raise the analytical operation efficiency and provide scientific information. Hence, it is rapidly attracting analyst attention and is used for simultaneous determination of multi-components in recent years ${ }^{6}$. Among the various chemometric approaches applied to multi-component analysis, partial least squares (PLS) has been successfully adopted in many quantitative assays. PLS is a factor analysis method which allows establishing a relationship between matrices of chemical data 7 . One of the clearest explanations of this method was given by Haaland and Thomas ${ }^{8}$. In PLS, the response data decomposition is weighted to the concentration. The aim of this work was to establish a simple, selective, sensitive, and robust RP-HPLC method for simultaneous determination of $\mathrm{Fe}(\mathrm{III})$ and $\mathrm{Hg}(\mathrm{II})$ in real samples, applying 1,4-bis-(4Pyridil)-2,3-diazo-1,3-butadiene (4-bpdb) (Figure 1) as a new ligand. The obtained data were processed by PLS technique.

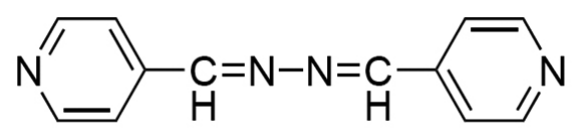

Figure 1- Schematic structure of (4-bpdb)

\section{EXPERIMENTAL}

\section{Apparatus and Materials}

The HPLC (KNAUER, Germany) instrument was equipped with a Mod.7125 Rheodyne injector with a $20 \mu 1$ external loop and a K2500 UVVisible detector at $228 \mathrm{~nm}$ wavelength. Vertex (KNAUER Co.) reversed-phase $\mathrm{C}_{18}$ analytical column $(250 \mathrm{~mm} \times 4.6 \mathrm{~mm}$ i.d., $5 \mu \mathrm{m}$ particle size $)$ was applied at $25^{\circ} \mathrm{C}$. Isocratic elution was performed (flow-rate: $1 \mathrm{ml} \mathrm{min}^{-1}$ ). A B2000 pH meter equipped with a GCFC 11 combination glass electrode was used for $\mathrm{pH}$ measurements. The 4-bpdb chelating agent was prepared by the method reported previously9. HPLC grade methanol was from Merck (Germany). All solutions were prepared by HPLC grade water, being filtered by a $0.45 \mu$ PTFE filter. Other reagents were of analytical grade unless stated otherwise.

\section{General Analysis Procedure}

A $0.05 \mathrm{mmol} \mathrm{L}^{-1}$ solution of $4-\mathrm{bpdb}$ was prepared by methanol:water (10:90) as the mobile phase. The $\mathrm{pH}$ was adjusted at 4.5 using $30 \mathrm{mmol} \mathrm{L}^{-1}$ of sodium acetate-acetic acid buffer. The capacity factors were calculated using $k$ $=\left(t_{r}-t_{0}\right) / t_{0}$, where $t_{r}$ is the average retention time of sample solute and $t_{0}$ is that of a non-absorbed substance (nitrate ion here)

\section{Partial Least Squares (PLS)}

PLS regression is an important multivariate calibration tool based on the use of a large number of variables, which permits to evaluate the concentration of interesting analytes. The PLS method is an important multivariate calibration tool that has been growing in importance for the last years and has been incorporated in new analytical chemistry textbooks ${ }^{10}$. PLS regression is based on the resolution of two initial multivariate matrices, $R$ (response matrix) and $C$ (concentration matrix), by projection onto smaller matrices $T$ and $U$ (or $R$ and $C$ score matrices, respectively). They contain the coordinates of the objects on the new axes or PLS components, with orthogonal columns, and relates the information in the response matrix $R$ to the concentration matrix $C$, through correlation between $R$ and $C$ covariance matrices. In this work, $R$ represents the independent variables (the original chromatographic data of the calibration set), while $C$ represents the dependent variables (concentration of analytes in the calibration set). The determination of a significant number of model dimensions (number of PLS principal components) was made by crossvalidation. The PLS method was employed using chromatographic data. ${ }^{11}$. 


\section{RESULTS AND DISCUSSIONS}

\section{Investigating Experimental Chromatography Conditions}

Standard solution of each analyte and a binary mixture solution were prepared by dissolving $\mathrm{Hg}\left(\mathrm{CH}_{3} \mathrm{COO}\right)_{2}$ and $\mathrm{Fe}\left(\mathrm{NO}_{3}\right)_{3} \cdot \mathrm{H}_{2} \mathrm{O}$ in the mobile phase (methanol:water, 10:90). As observed in figure 2, $\mathrm{Hg}$ (II) demonstrates 2 chromatographic signals according to formation of [M(4-bpdb)] and [M(4bpdb) ] complexes but $\mathrm{Fe}(\mathrm{III})$ does not form any complex and thus appears at $\mathrm{t}$ In RP-HPLC, the behavior of analytes is estimated according to their polarity, because the retention is mainly dependent on the partition between non-polar stationary phase and polar mobile phase.

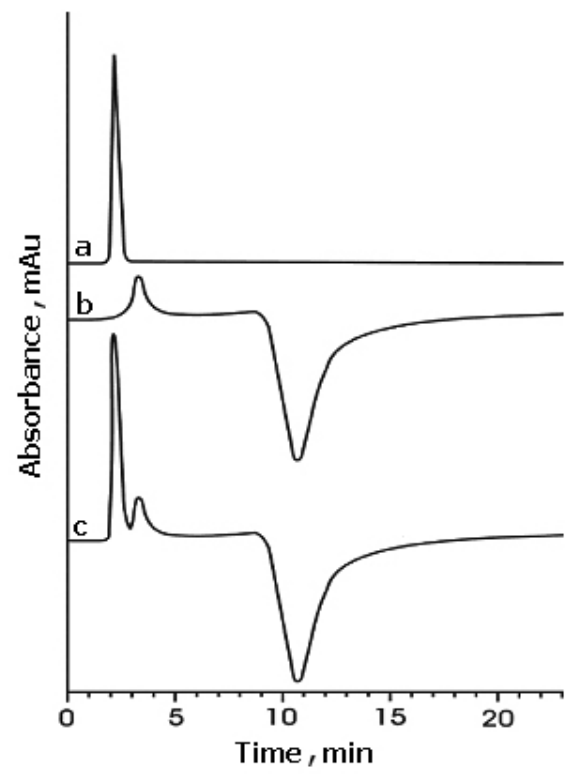

Figure 2- Chromatograms of a: $\mathrm{Fe}(\mathrm{III}), \mathrm{b}: \mathrm{Hg}(\mathrm{II})$ and c: binary mixture of $\mathrm{Fe}(\mathrm{III})$ and $\mathrm{Hg}(\mathrm{II})$

According to preliminary experiments, acetate buffer was selected as the suitable reagent for the experimental. Phosphate, citrate, formiate and acetate buffers $\left(30 \mathrm{mmol} \mathrm{L}^{-1}\right)$ were separately added to water:methanol $(90: 10)$ containing $0.1 \mathrm{mmol} \mathrm{L}^{-1}$ of 4-bpdb chelating agent. Phosphate causes $\mathrm{Hg}$ to sediment, citrate would demonstrate long time of analysis (more than $20 \mathrm{~min}$ ) and the chromatographic signals of $\mathrm{Hg}$ (II) and Fe (III) would highly overlap using formiate as the buffer. In the next step, the effect of $\mathrm{pH}$ on separation of $\mathrm{Fe}(\mathrm{III})$ and $\mathrm{Hg}(\mathrm{II})$ ions was studied in the 2.5-7.5 range, using acetate buffer solution $\left(30 \mathrm{mmol} \mathrm{L}^{-1}\right), \mathrm{HCl}\left(1 \mathrm{~mol} \mathrm{~L}^{-1}\right)$ and $\mathrm{NaOH}\left(1 \mathrm{~mol} \mathrm{~L}^{-1}\right)$. It was observed that gradually increment of eluent's $\mathrm{pH}$ from 2.5 to 5.5 would increase the resolution of analytes' signals but higher $\mathrm{pH}$ is no more effective (Figure 3).

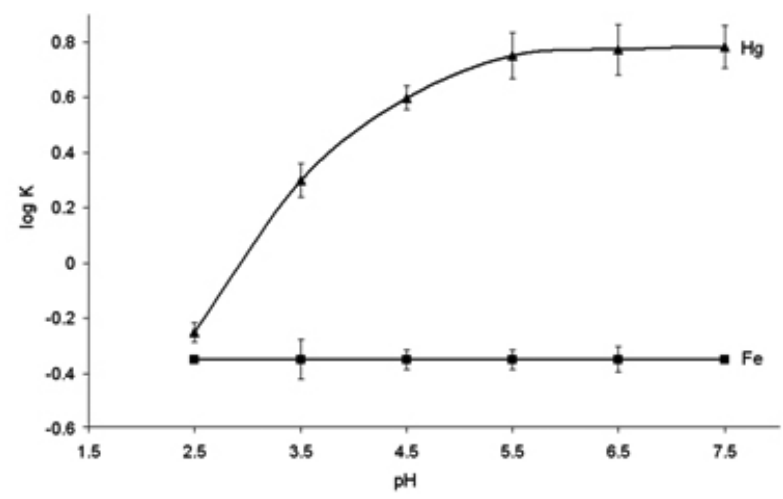

Figure 3- Effect of mobile phase's $\mathrm{pH}$ on capacity factor
In addition, buffer concentrations over $40 \mathrm{mmol} \mathrm{L}^{-1}$ are not influential on the resolution of analytes while concentrations below $20 \mathrm{mmol} \mathrm{L}^{-1}$ would decrease it (Figure 4). Thus $\mathrm{pH}=4.5$ and buffer concentration of $30 \mathrm{mmol} \mathrm{L}^{-1}$ were set as the optimum condition. Effect of eluent composition on resolution was studied changing the water:methanol ratio from 90:10 to $50: 50 \mathrm{v} / \mathrm{v}$. (containing 0.05 $\mathrm{mmol} \mathrm{L}^{-1}$ (4-bpdb) at $\mathrm{pH}=4.5$ ). Increasing the methanol content would decrease the peak widths and resolution. A perfect separation $(\mathrm{Rs}=3)$ was obtained by $10 \%$ methanol content (Figure 5). Concentration of $4-\mathrm{bpdb}$ was varied (0.0063-0.3000 $\left.\mathrm{mmol} \mathrm{L}^{-1}\right)$ in the mobile phase. In $0.05 \mathrm{mmol} \mathrm{L}^{-1} 4$-bpdb ligand concentration, analysis time and peak widths are optimum. The increasing of (4-bpdb) concentration over $0.05 \mathrm{mmol} \mathrm{L}^{-1}$ would decrease the resolution and sensitivity (according to high matrix absorbance) (Figure 6).

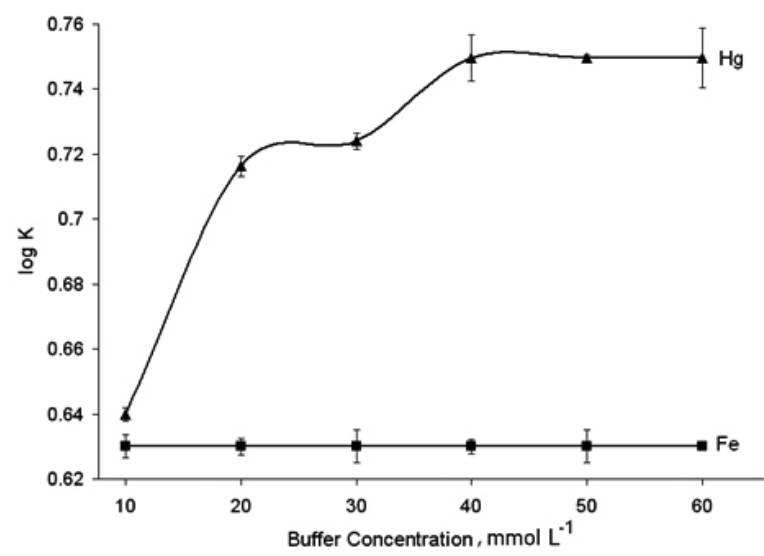

Figure 4- Effect of buffer concentration (acetate) on capacity factor

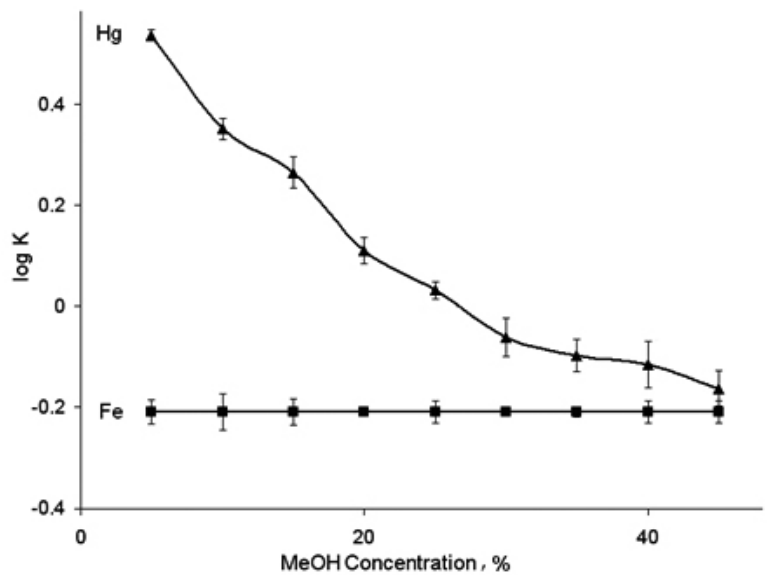

Figure 5- Effect of $\mathrm{MeOH}$ content in mobile phase on capacity factor

\section{Classical RP-HPLC Determination of Hg (II) and Fe (III)}

Figure 2-c shows 3 main signals around 2 and $11 \mathrm{~min}$; The first signal is related to $\mathrm{Fe}(\mathrm{III})$ and others of due to $\mathrm{Hg}(\mathrm{II})$. Classical calibration models were constructed, applying binary standard solutions of Fe(III) $(0.2-1.0 \mathrm{mmol}$ $\left.\mathrm{L}^{-1}\right)$ and $\mathrm{Hg}(\mathrm{II})\left(3.00-15.00 \mathrm{mmol} \mathrm{L}^{-1}\right)$. Both of the $\mathrm{Hg}(\mathrm{II})$ chromatographic signals were observed to be linearly related to the analyte's concentration. As the interference of $\mathrm{Fe}$ (III) and $\mathrm{Hg}$ (II) chromatographic signals at 1.50-3.50 min region would cause some errors in classical determination, the $1^{\text {st }}$ and $3^{\text {rd }}$ chromatographic signals (Figure 2-c) were used for quantitative determination of $\mathrm{Fe}(\mathrm{III})$ and $\mathrm{Hg}(\mathrm{II})$ ions respectively. The obtained quantification equations for analytes according to classical method are as:

$h(\mathrm{~cm})=340.65 \mathrm{C}_{\mathrm{Fe}}+9.66$

$h(\mathrm{~cm})=15.31 C_{\mathrm{Hg}}-1.95$ 


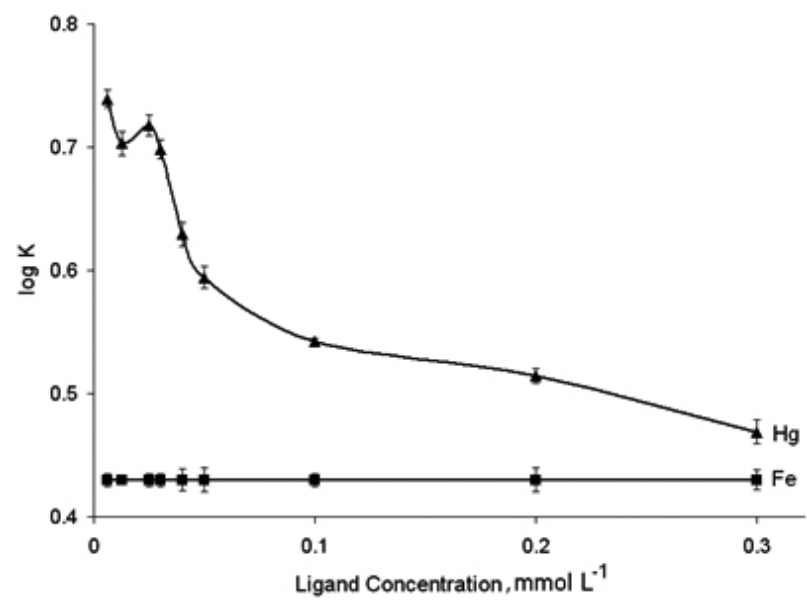

Figure 6- Effect of ligand (4-bpdb) concentration on capacity factor

where $h$ is the signal height and $C$ is the analyte's concentration. $\mathrm{R}^{2}$ and RSD (3 times analysis) for Fe (III) and $\mathrm{Hg}$ (II) were $(0.993,0.935 \%$ ) and $(0.992,1.257 \%)$ respectively. The LOD obtained by

$\mathrm{C}_{\mathrm{LOD}}=3 \mathrm{~S}_{\mathrm{b}} \mathrm{m}^{-1}$

where $S_{b}$ is standard deviation of blank for 10 replicate determination and $m$ is the slop in the regression equations. The LOD was $4.11 \times 10^{-3} \mathrm{mmol} \mathrm{L}^{-1}$ and $9.14 \times 10^{-2} \mathrm{mmol} \mathrm{L}^{-1}$ for $\mathrm{Fe}(\mathrm{III})$ and $\mathrm{Hg}(\mathrm{II})$, respectively.

\section{Partial Least Squares Technique}

The main advantage of multivariate analysis using Partial Least Squares (PLS) calibration is its ability in fast determination of the components in mixtures especially with signal overlapping. Among chemometrics methods, partial least squares technique (PLS) has been used frequently according to quality of the obtained calibration models, ease of its implementation and software availability ${ }^{12}$. Thus it was very useful to take the advantage of chemometrics in our research, improving the idea by its benefits.

4. Calibration Model for RP-HPLC Analysis, Utilizing PLS

A set of 20 binary standard solutions were provided $\left(0.20-1.00 \mathrm{mmol} \mathrm{L}^{-1}\right.$ of Fe and 3.00-15.00 $\mathrm{mmol} \mathrm{L}^{-1}$ of $\mathrm{Hg}$ ). Twelve standard solutions were used to set up the calibration model and the remaining 8 solutions were used as the validation set to evaluate the calibration models. The investigated retention time region was 1.80-4.30 min. Chromatograms were obtained according to the procedure detailed before. The root mean square error (RMSE) is an indication of average error for each of components in analysis and thus was calculated. Tables 1 and 2 show the actual and predicted concentration of analytes in addition with $\mathrm{R}^{2}$ and RMSE for both calibration and validation samples. The constructed calibration model was optimized by varying the number of PLS factors from 1 to 6 . Cross validation method, leaving out one sample at a time, was used to select the optimum number of factors in the PLS algorithm. Cross validation makes the calibration set as large and representative as possible. The prediction error sum of squares (PRESS) was calculated each time a new factor was added. The optimum number of factors would yield the minimum PRESS. In the finalized model, optimum number of factors was 4 in the model for both of analytes. The PLS algorithm was also applied to an independent data set consisting of 6 samples (Fe(III): $0.30-0.80 \mathrm{mmol} \mathrm{L}^{-1}$ and $\mathrm{Hg}(\mathrm{II}): 3.00-15.00$ $\mathrm{mmol} \mathrm{L}^{-1}$ ) in the proposed method. Root mean square error of test (RMSET) for independent data set was 0.024 and 0.393 for $\mathrm{Fe}(\mathrm{III})$ and $\mathrm{Hg}$ (II) respectively.

\section{Analysis of Real Samples and Recovery Study}

In order to evaluate the ability of the proposed method for quantification of $\mathrm{Fe}(\mathrm{III})$ and $\mathrm{Hg}(\mathrm{II})$ in real analysis, variety of samples consisting of mineral water and pharmaceuticals (tablet and syrup) were analyzed, applying standard addition and recovery study. RSD of analytical procedures was determined by 5 times of replication in each experiment. Results are detailed in tables 3 and 4
Table 1- The results obtained for standard samples in calibration set.

\begin{tabular}{|c|c|c|c|c|}
\hline \multirow{2}{*}{ Sample } & \multicolumn{2}{|c|}{$\mathrm{Fe}\left(\mathrm{mmol} \mathrm{L}^{-1}\right)$} & \multicolumn{2}{|c|}{$\mathrm{Hg}\left(\mathrm{mmol} \mathrm{L}^{-1}\right)$} \\
\hline & Actual & Predicted & Actual & Predicted \\
\hline 1 & 0.20 & 0.20 & 3.00 & 3.62 \\
\hline 2 & 1.00 & 1.03 & 15.00 & 14.31 \\
\hline 3 & 0.40 & 0.42 & 12.00 & 13.12 \\
\hline 4 & 0.20 & 0.20 & 6.00 & 6.28 \\
\hline 5 & 0.40 & 0.41 & 3.00 & 2.81 \\
\hline 6 & 0.40 & 0.41 & 12.00 & 11.55 \\
\hline 7 & 0.60 & 0.60 & 9.00 & 8.79 \\
\hline 8 & 0.60 & 0.59 & 15.00 & 14.79 \\
\hline 9 & 0.80 & 0.78 & 6.00 & 5.61 \\
\hline 10 & 0.80 & 0.81 & 9.00 & 9.12 \\
\hline 11 & 0.80 & 0.86 & 9.00 & 9.20 \\
\hline 12 & 1.00 & 0.97 & 12.00 & 11.16 \\
\hline RMSEC & \multicolumn{2}{|c|}{0.025} & \multicolumn{2}{|c|}{0.559} \\
\hline $\mathrm{R}^{2}$ & \multicolumn{2}{|c|}{0.988} & \multicolumn{2}{|c|}{0.933} \\
\hline
\end{tabular}

Table 2- Actual and predicted concentrations for validation set by the optimized PLS model.

\begin{tabular}{|c|c|c|c|c|}
\hline \multirow{2}{*}{ Sample } & \multicolumn{2}{|c|}{$\mathrm{Fe}\left(\mathrm{mmol} \mathrm{L}^{-1}\right)$} & \multicolumn{2}{c|}{$\mathrm{Hg}\left(\mathrm{mmol} \mathrm{L}^{-1}\right)$} \\
\cline { 2 - 5 } & Actual & Predicted & Actual & Predicted \\
\hline 13 & 0.40 & 0.44 & 3.00 & 2.90 \\
\hline 14 & 0.40 & 0.44 & 12.00 & 11.60 \\
\hline 15 & 0.60 & 0.64 & 9.00 & 9.14 \\
\hline 16 & 0.60 & 0.61 & 15.00 & 14.71 \\
\hline 17 & 0.80 & 0.77 & 6.00 & 5.58 \\
\hline 18 & 1.00 & 1.04 & 12.00 & 13.63 \\
\hline 19 & 0.20 & 0.19 & 3.00 & 2.54 \\
\hline 20 & 0.20 & 0.22 & 12.00 & 11.55 \\
\hline RMSEV & \multicolumn{2}{|c|}{0.034} & & \multicolumn{2}{c|}{0.709} \\
\hline $\mathrm{R}^{2}$ & \multicolumn{2}{|c|}{0.982} & & \multicolumn{2}{c|}{} \\
\hline
\end{tabular}

Table 3- Determination of Fe(III) in real samples by RP-HPLC and PLS

\begin{tabular}{|c|c|c|c|c|}
\hline & $\begin{array}{l}\text { Added Std. } \\
\left(\mathrm{mmol} \mathrm{L}^{-1}\right)\end{array}$ & $\begin{array}{c}\text { Predicted } \\
\left(\mathrm{mmol} \mathrm{L}^{-1}\right)\end{array}$ & $\begin{array}{c}\text { Recovery } \\
(\%)\end{array}$ & RSD (\%) \\
\hline \multirow{3}{*}{ Mineral Water } & 0.40 & 0.39 & 99.52 & 1.05 \\
\hline & 0.80 & 0.77 & 97.23 & 1.06 \\
\hline & 0.30 & 0.30 & 101.08 & 0.98 \\
\hline \multirow{4}{*}{$\begin{array}{c}\text { Ferrous Sulfate } \\
\text { Tablet } \\
(0.20 \mathrm{mmol} \\
\left.\mathrm{L}^{-1}\right)\end{array}$} & 0.00 & 0.23 & 95.94 & 2.12 \\
\hline & 0.20 & 0.40 & 93.32 & 1.48 \\
\hline & 0.40 & 0.58 & 94.50 & 1.76 \\
\hline & 0.60 & 0.76 & 95.98 & 1.52 \\
\hline \multirow{4}{*}{$\begin{array}{l}\text { Ferrous Sulfate } \\
\text { Syrup }(50 \\
\text { mmol L-1) }\end{array}$} & 0.00 & 0.43 & 90.25 & 1.51 \\
\hline & 0.16 & 0.61 & 94.50 & 0.88 \\
\hline & 0.24 & 0.68 & 92.25 & 0.91 \\
\hline & 0.30 & 0.72 & 89.25 & 1.01 \\
\hline
\end{tabular}

Table 4- Determination of $\mathrm{Hg}(\mathrm{II})$ in real samples by RP-HPLC and PLS

\begin{tabular}{|c|c|c|c|c|}
\hline & $\begin{array}{c}\text { Added Std. } \\
\left(\mathrm{mmol} \mathrm{L}^{-1}\right)\end{array}$ & $\begin{array}{c}\text { Predicted } \\
\left(\mathrm{mmol} \mathrm{L}^{-1}\right)\end{array}$ & $\begin{array}{c}\text { Recovery } \\
(\%)\end{array}$ & RSD (\%) \\
\hline Mineral & 12.00 & 11.67 & 97.52 & 2.33 \\
Water & 3.00 & 2.95 & 98.42 & 2.01 \\
& 15.00 & 13.99 & 93.30 & 4.32 \\
\hline
\end{tabular}

\section{CONCLUSIONS}

A new method was introduced for separation and simultaneous determination of $\mathrm{Fe}(\mathrm{III})$ and $\mathrm{Hg}(\mathrm{II})$, which produced reliable and reproducible results. Different chemical matrices were also analyzed by the proposed method, obtaining acceptable data. PLS chemometric technique provides the 
ability in performing the determination process in the first 5 minutes of elution times, resolving the problem of interfering chromatographic signals. The analytes can be sensitively determined without any matrix ion effect. The PLS benefited RP-HPLC method can be applied for simultaneous determination of $\mathrm{Fe}(\mathrm{III})$ and $\mathrm{Hg}$ (II) in different environmental samples.

\section{REFERENCES}

1. Morita, M.; Yoshinaga, J.; Edmonds, J.S. Pure Appl. Chem. 1998, 70, 1585 .

2. de Baar H.J.W., de Jong J.T.M., in The Biogeochemistry of $\mathrm{Fe}$ in Seawater (IUPAC Book Series on Analytical and Physical Chemistry of Environmental Systems), edited by Turner, D.; and Hunter, K., JohnWiley \& Sons, Chichester, 2001.
3. Marco, S.G.; Cremonini, M.A.; Esteban, P.; Yunta, F.; Apaolaza, L.H.; Placucci, G.; Lucena, J.J. J. Chromatogr. A 2005, 1064, 57.

4. Johanson, M.; Emteborg, H.; Glad, B.; Reinholdsson, F.; Baxter, D.C. Fresenius J. Anal. Chem. 1995, 351, 461.

5. Hadad, G.M.; El-Gindy, E.; Mahmoud, W.M.M. Spectrochim Acta A 2008, 70, 655 .

6. Fang, G.; Liu, N. Anal. Chim. Acta 2001, 445, 245.

7. Ragno, G.; Ioele G.; Risoli, A. Anal. Chim. Acta 2004, 512, 173.

8. Haaland, D.M.; and E.V. Thomas, Anal. Chem. 1988, 60, 1193.

9. Kesslen, E.C.; Euler, W.B. Tetrahedron Lett., 1995, 36, 4725.

10. Kellner, R.; Mermet, J.M.; Otto, M.; Valcarcel, M.; Widmer, H.M. Analytical Chemistry, (Wiley-VCH, Weinheim, 2004).

11. Pylypiw, H.M.; Grether, M.T. J. Chromatogr. A 2000, 883, 299.

12. Goicoechea, H.C.; Olivieri, A.C. Analyst 2001, 126, 1105. 